\title{
Engineering Properties of Foamed Concrete Containing Water Repellent
}

\author{
Yee Ling Lee ${ }^{1 *}$, Chen Hoe $\mathrm{Oh}^{1}$, Ming Han $\mathrm{Lim}^{l}$ and Foo Wei Lee \\ ${ }^{1}$ Lee Kong Chian Faculty of Engineering and Science, Universiti Tunku Abdul Rahman, Jalan Sungai \\ Long, Bandar Sungai Long, Cheras, 43000 Kajang, Selangor, Malaysia
}

\begin{abstract}
Concrete plays a vital role in the construction industry. Over the years, increasing demands from the construction industry had led to the birth of various types of concrete. Foamed concrete is one of the variations of lightweight concrete and yields a high percentage of porosity due to the internal presence of multiple air bubbles. Consequently, foamed concrete is prone to harmful substances' penetration, which will disrupt its overall durability and the purpose of usage. Hence, water repellent is introduced into foamed concrete in this study and its effect on various engineering properties of foamed concrete will be investigated. The objectives of this study are to obtain optimum water-to-cement ratio for the $1200 \mathrm{~kg} / \mathrm{m}^{3}$ foamed concrete and to study the impacts of water repellents on the fresh and engineering properties of foamed concrete. This study was separated into two main research phases. The first phase aimed at determining the optimum water-to-cement ratio for foamed concrete without the presence of water repellents, which was then determined as 0.48 . The continuation of this research exhibited the utilization of the obtained optimum water-tocement ratio from the first phase of the study to delve into the impact analysis of $0.2 \%$ and $0.4 \%$ calcium stearate (CS) on the fresh and engineering properties of foamed concrete. The incorporation of CS into foamed concrete had affected its mechanical properties in terms of compressive strength. However, it had played a vital role in improving the foamed concrete's physical properties in terms of absorption, initial surface absorption and sorptivity. It was also found that the recommended dosage for CS incorporation was determined as $0.2 \%$ of cement weight as to prevent the adverse effects from overdosing of water repellents.
\end{abstract}

\section{Introduction}

Concrete is one of the most common and important material that is widely used in the construction industry [1]. It is made by mixing the components together in an appropriate proportion and a very strong bond will be formed between the mixtures after a certain period. However, normal concrete is relatively heavy in terms of its self-weight and has caused increased expenses in construction projects due to the enlargement of columns and foundations required to support heavy loads. Over the years, increasing demands from the

\footnotetext{
*Corresponding author: yllee@utar.edu.my
} 
construction industry had led to continuous research and production of various types of concrete in order to cater to different needs of the construction industry. In an attempt to tackle the above issue, lightweight concrete is one of the invention with the purpose of reducing building's dead loads together with the ultimate target of cutting total costs involved in a construction project.

Foamed concrete is also known as cellular concrete. It has an even lower concrete density among other lightweight concrete and is usually in the range of less than 1400 $\mathrm{kg} / \mathrm{m}^{3}$ [2]. As the name goes, foamed concrete has high percentage of air voids present in the form of stable foams inside the cement paste mixture. The cement paste mixture has sand, cement and water without the presence of coarse aggregates in order to keep it light. This makes it similar to mortar mixture and it is a free flowing paste. Foamed concrete has a wide variety of applications in the construction industry. The density of foamed concrete can be controlled by varying the amount of sand, cement and foam generated in the mixture. The concrete density will be lower if more foam is present inside foamed concrete. This also reveals that foamed concrete is a type of lightweight material consisting of cement paste and a homogeneous void structure created by air voids, which are then entrapped within the mortar mix together with the help of foaming agents [3]. The structure of foamed concrete is characterized by the formation of macropores and micropores in the concrete mixture [4]. Pores with diameter of above $60 \mu \mathrm{m}$ is classified as macropores [5]. Macropores are formed due to mass expansion during aeration process of foamed concrete, whereas micropores are formed in between walls of macropores [6].

However, it is known that water tends to get absorbed into the foamed concrete easily due to its high amount of air voids available inside the concrete. Since Malaysia is a tropical country, a relatively high humidity is maintained as abundance of precipitation is experienced over the year. This type of weather condition is not favourable towards the usage of foamed concrete in construction industry as it will cause the foamed concrete to get exposed to moisture easily. The water absorption into foamed concrete will cause it to lose the intended purpose of usage and its durability as a lightweight material in construction industries.

Calcium stearate (CS) is one of the water repellent chemicals that is utilized for this research. It is a type of oil-based water repellent admixture and has been used in production of concretes for many years [7]. It provides the lightweight foamed concrete with water repellent property by generating hydrophobic layers on all possible surfaces [8]. Besides that, the addition of CS into concrete also helped to minimize the corrosion from the attack of chloride ions and preventing algal fouling on cellular concrete by reducing the moisture absorption using water repellent [9-10].

Besides that, the air bubbles are extremely fragile and will break easily. So, they have to be isolated properly in order to maintain the strength of foamed concrete. The air voids need to be well-maintained to keep the foamed concrete to its lightweight properties. Therefore, a study regarding the addition of water repellent into a $1200 \mathrm{~kg} / \mathrm{m}^{3}$ foamed concrete will be carried out in order to obtain the optimum water-to-cement ratio and to determine the effect of water repellent on its engineering properties.

\section{Materials and method of testing}

\subsection{Materials preparation}

Ordinary Portland Cement (OPC) was used throughout the study. The OPC used complied with Type I Portland cement as per in ASTM C150 (2007). Quarry sand, which was exposed directly to the natural weathering, was oven dried at a temperature of $150^{\circ} \mathrm{C} \pm 5^{\circ} \mathrm{C}$ 
for 24 hours before undergoing the sieve analysis. The sand used in this study was sieve by $100 \%$ pass through $0.60 \mathrm{~mm}$ sieve size. The quantity of sand was calculated based on the cement-sand ratio 1:1. Silica fume (SF) was employed as a partial cementitious replacement material and fixed at $10 \%$ of cement weight used in this study. The dimension of the Polypropylene fiber (PP) used is $19 \mathrm{~mm}$ Mega Mesh I fibrillated polypropylene fiber to enhance the strength of the foamed concrete. The amount of usage for PP fiber was fixed at $0.1 \%$ of the cement weight used in casting the foamed concrete.

Other than that, calcium stearate (CS) was utilized as the water repellent to provide the foamed concrete with hydrophobic characteristics. CS is a type of oil-based water repellent and has a low solubility in water. For the control mix, no water repellent was added, whereas the subsequent samples had an increase of calcium stearate dosage by an interval of $0.2 \%$ and $0.4 \%$ of cement weight used respectively. Superplasticizer (SP) is also known as high range water reducer or retarder. In this research, polycarboxylic ether with fixed portion of $1 \%$ of the cement weight. Besides that, the foam is produced by using locally manufactured synthetic-based foaming agent and water with the ratio of 1:30. The foaming agent is compressed at a pressure of $0.5 \mathrm{MPa}$ in foam generator to produce a stable bubble to control the density of the foam concrete.

\subsection{Mix proportions}

Table 1. Mix Proportions for the Series of Foamed Concrete

\begin{tabular}{|c|c|c|c|c|c|c|c|c|}
\hline \multicolumn{9}{|l|}{ Stage 1} \\
\hline $\begin{array}{l}\text { Mix } \\
\text { Designation }\end{array}$ & $\mathbf{w} / \mathbf{c}$ & $\begin{array}{l}\text { Cement } \\
\left(\mathrm{kg} / \mathrm{m}^{3}\right)\end{array}$ & $\begin{array}{l}\text { Sand } \\
\left(\mathrm{kg} / \mathrm{m}^{3}\right)\end{array}$ & $\begin{array}{l}\text { Water } \\
\left(\mathbf{k g} / \mathrm{m}^{3}\right)\end{array}$ & $\begin{array}{l}\text { SF } \\
\left(\mathrm{kg} / \mathrm{m}^{3}\right)\end{array}$ & $\begin{array}{l}\text { SP } \\
\left(\mathrm{kg} / \mathrm{m}^{3}\right)\end{array}$ & $\begin{array}{l}\text { PP } \\
\left(\mathrm{kg} / \mathrm{m}^{3}\right)\end{array}$ & $\begin{array}{l}\text { CS } \\
\left(\mathrm{kg} / \mathrm{m}^{3}\right)\end{array}$ \\
\hline $\mathrm{FC} 0-0.44$ & 0.44 & 492 & 492 & 216 & 49.2 & 4.92 & 0.49 & 0 \\
\hline $\mathrm{FC} 0-0.46$ & 0.46 & 488 & 488 & 224 & 48.8 & 4.88 & 0.48 & 0 \\
\hline $\mathrm{FC} 0-0.48$ & 0.48 & 484 & 484 & 232 & 48.4 & 4.84 & 0.48 & 0 \\
\hline FC0-0.50 & 0.50 & 480 & 480 & 240 & 48.0 & 4.80 & 0.48 & 0 \\
\hline \multicolumn{9}{|l|}{ Stage 2} \\
\hline FC0 & 0.48 & 484 & 484 & 232 & 48.4 & 4.84 & 0.48 & 0 \\
\hline $\mathrm{FC} 0.2$ & 0.48 & 484 & 484 & 232 & 48.4 & 4.84 & 0.48 & 0.97 \\
\hline FC0.4 & 0.48 & 484 & 484 & 232 & 48.4 & 4.84 & 0.48 & 1.94 \\
\hline
\end{tabular}

There were total of two stages experimental work had been conducted in this study. For Stage 1 , it is a trial mix to obtain the optimum water-cement ratio for the lightweight foamed concrete. In this stage, the mix proportions were constant with a cement-to-sand ratio of 1:1 while the water-to-cement ratio will be varied from 0.44 to 0.50 with an increasing interval of 0.02 . For trial mix, no water repellent was added at all. Each of the samples with varying water-to-cement ratio was then tested for their 7 days strength respectively. The trial mix was done in pursue of the optimum water-to-cement ratio for the final mix proportions justified by the best overall compressive strength, consistency and stability that were obtained.

In Stage 2, after obtaining the optimum water-cement ratio with its spread value (reference mix) in stage 1, CS was add into the mix proportion with $0.2 \%$ and $0.4 \%$ of total cement weight. Table 1 shows the mix proportions for the series of foamed concrete 
investigated in this study. The mix proportion for foamed concrete was calculated based on $1 \mathrm{~m}^{3}$ volume.

\subsection{Mixing procedures}

The preparation of lightweight foamed concrete initially start with the preparation of the mortar slurry. The dry materials such as cement, sand, silica fume, polypropylene fiber and calcium stearate was mixed thoroughly. Then, the measured water with superplasticizer was added and mixed uniformly. This was followed by preparation of foam from a pre-mixed foaming agent. Foam was produced by introducing a compressed air of $0.5 \mathrm{MPa}$ through the nozzle of a foam generator. Prior the introduction of foam to the mortar slurry, the density of the mortar was determined by pouring the mortar into a known volume container to measure its weight. This is to ensure accurate amount of foam to be added. After the mortar and foam were blended uniformly, the weight of foamed concrete was measure again for its fresh density. The fresh lightweight foamed concrete was then left for 24 hours before de-moulding. After de-moulding, all specimens were cured for 7-day and 28-day with water curing before commenced for respective engineering properties test.

\subsection{Testing methods}

\subsubsection{Fresh properties test}

Prior introduce the foam into the mortar slurry, flow table test was performed to the check the workability and consistency. The flow table test is in accordance to ASTM C230 [11]. The mortar sample was placed on a flow table and dropped 25 times within 15 seconds. After dropped for 25 times, the cone is lifted up and the mortar spread out on the flow table. The diameters for four angles of the spread mortar were measured and recorded.

\subsubsection{Compressive strength test}

Compressive strength test was conducted in compliance with BS EN 12390-3 [12]. The compressive strength test was performed using INSTRON 5582 Testing Machine. The cubic-shaped foamed concrete specimens with dimensions of $100 \mathrm{~mm}$ x $100 \mathrm{~mm} \times 100 \mathrm{~mm}$ were subjected to an axial compression load with a constant loading rate of $0.02 \mathrm{~mm} / \mathrm{s}$ until failure takes place.

\subsubsection{Water absorption test}

Water Absorption test was performed to determine the percentage of water absorption that can be achieved by the foamed concrete specimen. The test conducted in accordance with ASTM C642-13 [13]. Cubical specimen with dimensions of $100 \mathrm{~mm}$ x $100 \mathrm{~mm}$ x $100 \mathrm{~mm}$ were used to perform this test. The specimens were removed from curing tank and left indoor for 24 hours in order to allow it to achieve saturated surface dry condition. It was then weighed on calibrated weighing scale to acquire the saturated surface dry weight. The respective foamed concrete specimen was then oven-dried for 24 hours until bone-dry condition. The weight of bone-dry concrete specimen was measured and used to calculate the respective absorption of the concrete specimen. 


\subsubsection{Initial surface absorption test (ISAT)}

The initial surface absorption test (ISAT) was performed to determine the water absorption properties of the concrete. This test conducted in accordance with BS 1881-208 [14] with involves the water flow onto a designated surface area of the concrete specimen where, it is subjected to constant head and temperature. Cubic-shaped with dimension of $100 \mathrm{~mm} \times 100$ $\mathrm{mm} \times 100 \mathrm{~mm}$ concrete specimens were used to perform ISAT. Prior testing, the cube specimens were removed from curing tank and oven-dried for 24 hours. They were left at room temperature to cool down prior to clamping at the apparatus. A plastic cap was sealed to the surface and connected by a filter funnel and capillary tubes for the introduction of water onto the concrete surface as shown in Fig.1. The water level was retained at $200 \mathrm{~mm}$ height above the concrete surface by fixing the reservoir and capillary tubes at the specified height. The initial surface absorption was taken as the time taken to move 86 scaled divisions for every 10, 30, 60 and 120 minutes mark.

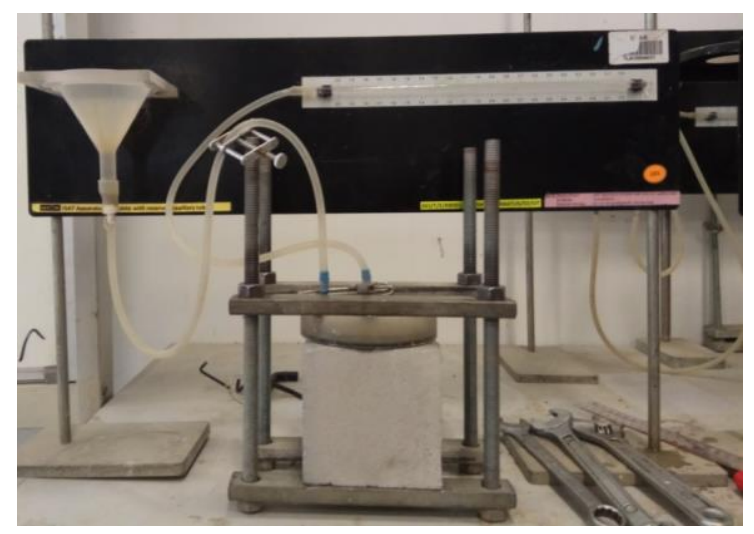

Fig. 1. Setup for ISAT.

\subsubsection{Sorptivity test}

Sorptivity test was conducted in accordance with ASTM C1585 [15] which, to determine the capacity of absorption of water by the foamed concrete through capillarity. Cylindrical shape with $100 \mathrm{~mm}$ diameter and $50 \mathrm{~mm}$ height specimens were used in this test. The concrete specimens were oven-dried for 24 hours and then left to cool down in desiccators for another 24 hours to prevent moisture contact. For this test, the top and sides of the ovendried specimen were covered with plastic sheets, whereas the base was partially immersed to a maximum depth of approximately $2 \mathrm{~mm}$ in water at room temperature by resting them on top of thin steel rods in a shallow tray. The respective increase in the specimen's weight at $1,5,10,20,30,60,120,180,240,300$ and 360 minutes mark was measured to determine the amount of water absorbed through the capillary pores of foamed concrete. In addition, the specimen weight was also measured at 1 day and 2 days of immersion respectively. 


\section{Results and discussion}

\subsection{Trial mix}

Table 2. Overall Trial Mix Results.

\begin{tabular}{|c|c|c|c|c|c|c|c|}
\hline $\begin{array}{l}\text { Mix } \\
\text { Designation }\end{array}$ & $\begin{array}{l}\text { W/C } \\
\text { Ratio }\end{array}$ & $\begin{array}{l}\text { Flow } \\
\text { Table } \\
\text { Test } \\
(\mathrm{mm})\end{array}$ & $\begin{array}{l}\text { Fresh } \\
\text { Density } \\
\left(\mathrm{kg} / \mathrm{m}^{3}\right)\end{array}$ & $\begin{array}{l}\text { Dry } \\
\text { Density } \\
\left(\mathbf{k g} / \mathbf{m}^{3}\right)\end{array}$ & Consistency & Stability & $\begin{array}{l}\text { Compressive } \\
\text { Strength } \\
\text { (MPa) }\end{array}$ \\
\hline FC0-0.44 & 0.44 & 187 & 1209 & 1242 & 1.01 & 0.97 & 2.30 \\
\hline FC0-0.46 & 0.46 & 196 & 1250 & 1226 & 1.04 & 1.02 & 3.00 \\
\hline FC0-0.48 & 0.48 & 228 & 1235 & 1206 & 1.03 & 1.03 & 3.57 \\
\hline FC0-0.50 & 0.50 & 228 & 1175 & 1269 & 0.98 & 0.92 & 2.31 \\
\hline
\end{tabular}

The water-to-cement ratio used during trial mix (Stage 1) to determine the optimum level is ranged from 0.44 to 0.50 . All the fresh density and dry density values were recorded and used to calculate their respective consistency and stability. The specimens are cured for 7 days before testing of its compressive strength. The overall trial mix results were tabulated in Table 2. In theory, consistency and stability of concrete are close to each other, giving an approximate ratio of 1 . The consistency of the fresh mixed foamed concrete determined by measuring the fresh density to designated density. For stability, it is measured by measuring the fresh density to hardened density. The hardened density of produced foamed concrete was kept in the range of $\pm 50 \mathrm{~kg} / \mathrm{m}^{3}$ of designated density.

From Table 2, it shows that the spread value increased when the water content was increased. This clearly indicated that the fluidity of foamed concrete is dependent on the amount of water in the mixes. In term of consistency and stability, FC0-0.44 have the nearest consistency to unity. However, in term of stability, FC0-0.44 have lower stability value than unity. This indicated that the foam bubble may burst during the hardened process as the dry density is higher that the fresh density. By comparing among the specimens, FC0-0.48 have the constant value of 1.03 for both consistency and stability.

In the comparison of 7-days cube compressive strength of foamed concrete with water-to-cement ratio from 0.44 to 0.50 , Table 2 shows that the average compressive strength of FC0-0.48 has the highest compressive strength among all the specimens, which was standing at 3.57 MPa. Besides that, among the results showed in Table 2, FC0-0.5 with the highest water-cement ratio shows lower compressive strength and poor consistency and stability. This proved that more slurry mixes brought to adversely effects on the consistency and uniformity of fresh mixes and hence affect its strength properties badly [16]. Overall, the optimal water-to-cement ratio for the trial mix was discovered as 0.48 . This was due to the best overall workability, stability, consistency, and compressive strength. The optimum water-to-cement ratio of 0.48 was then used as the reference point in the casting of the foamed concrete samples incorporated with CS in the Stage 2 of this study. 


\subsection{Compressive strength}

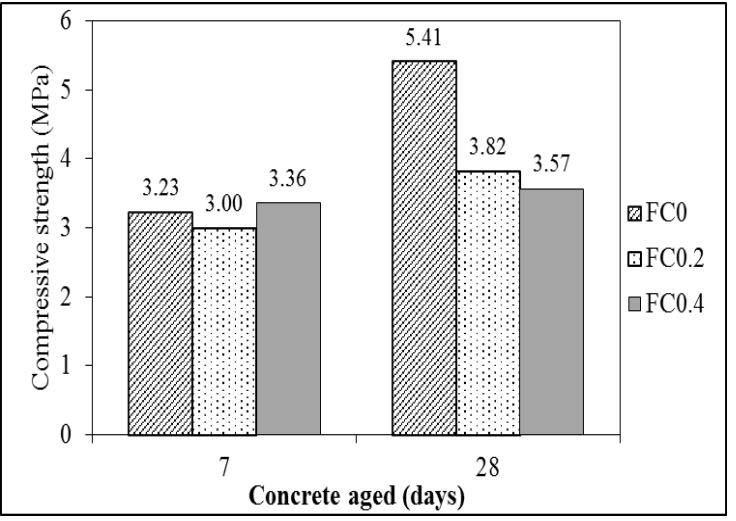

Fig. 2. Compressive Strength Development from 7 to 28 Days of Curing Age

Fig.2 showed that the compressive strength development trend was increasing for FC0 samples from 7 days to 28 days of curing. The 28 days compressive strength for FC0 stood at the highest point among all, which was $5.41 \mathrm{MPa}$. This was due to the continuous hydration process from water curing that forms C-S-H gel, contributing to the strength gain. In comparison, the compressive strength development in FC0.2 samples were increasing but at a slower pace throughout the 28 days curing period. The 28 days compressive strength for FC0.2 stood at $3.82 \mathrm{MPa}$, which was $29.39 \%$ lower than FC0. This may be due to the presence of the calcium stearate (CS) in the foamed concrete samples, which reduced the water absorption capabilities. Thus, the hydration process was retarded. On the other hand, the compressive strength development in FC0.4 had a relatively high early strength during 7 days of curing, standing at $3.36 \mathrm{MPa}$. However, the compressive strength at 28 days of curing age giving it a mere of $3.57 \mathrm{MPa}$, which was the lowest among all. This may due to the long term adverse effects from overdosing in the amount of CS added, which caused concrete did not complete the hydration process, cracks internally and hence reducing the final compressive strength.

\subsection{Water absorption}

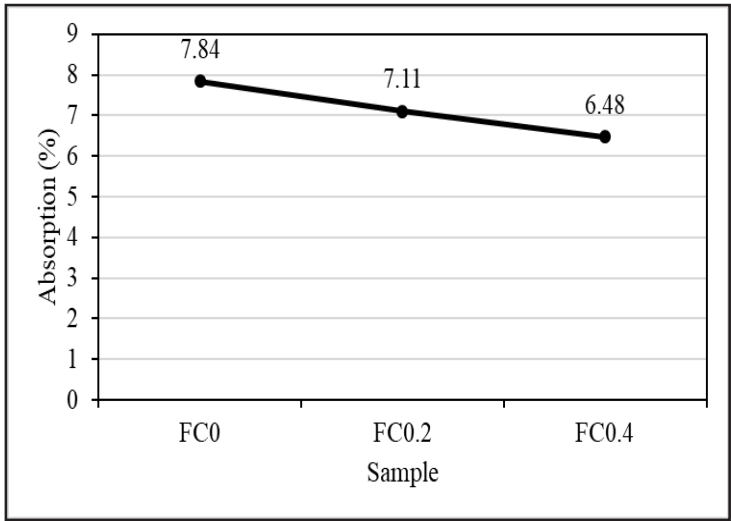

Fig. 3. 28-Days Percentage of Absorption 
Based on Fig. 3, the percentage absorption of FC0 samples was the highest with $7.83 \%$ among all the specimens. The samples of FC0.2 had seen a drop in its percentage absorption at $7.11 \%$, whereas the samples of $\mathrm{FC} 0.4$ had the lowest percentage absorption at only $6.48 \%$. The percentage absorption is decreased as the content of CS added is increased, showing an inversely proportional trend. This proved that CS had the effect on reducing the absorption capabilities on the foamed concrete samples and reduced about $9.3 \%$ and $17.3 \%$ for $\mathrm{FC} 0.2$ and $\mathrm{FC} 0.4$ respectively.

\subsection{ISAT}

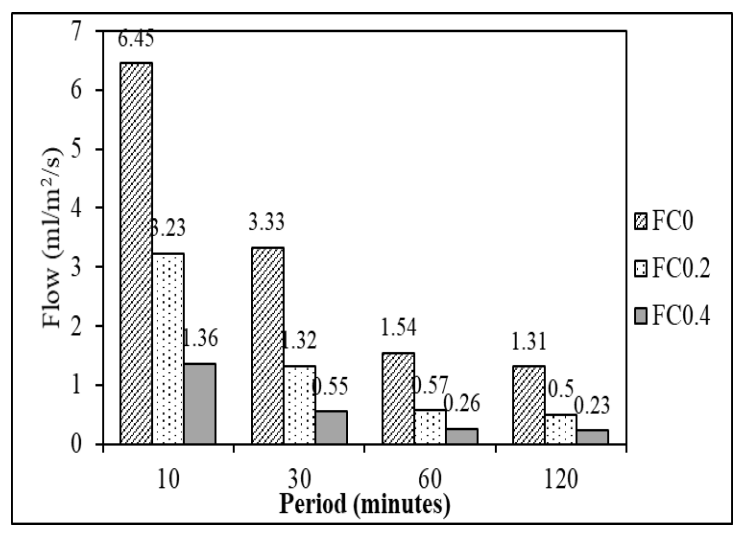

Fig. 4. 28-Days ISAT for FC0, FC0.2 and FC0.4

Based on Fig. 4, the incorporation of CS into lightweight foamed concrete had resulted in the drastic reduction of initial surface absorption of concrete. This was due to the increased water tightness of foamed concrete, contributed by the water repelling nature of CS. Besides that, Fig. 4 also shows a similar trend with the result of water absorption test in Fig. 3. The initial surface absorption of FC0.2 was $62 \%$ lower than that of FC0, whereas FC0.4 was $82 \%$ lower than that of FC0. Although FC0.4 had a lower initial surface absorption than FC0.2, FC0.4 had a slightly lower compressive strength. Thus, FC0.2 had better overall strength than FC0.4.

\subsection{Sorptivity}

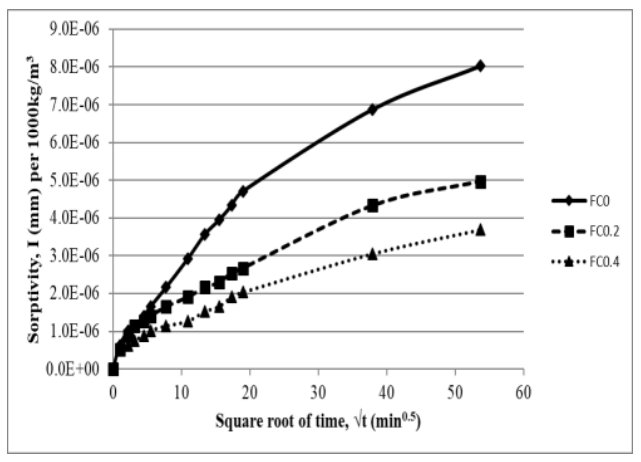

Fig. 5. 28-Days Sorptivity for FC0, FC0.2 and FC0.4 
The sorptivity values of all the specimens increased drastically from $0 \mathrm{~min}^{0.5}$ to $1 \mathrm{~min}^{0.5}$, followed by gradual increase after $2.24 \mathrm{~min}^{0.5}$, which were illustrated in Fig. 5. In comparison with $\mathrm{FC} 0$ with $\mathrm{FC} 0.2$ and $\mathrm{FC} 0.4$, it had shown the slope increment decrease with the increment dosage of CS. The slope of the respective curves in the chart was defined as the sorptivity coefficient. The sorptivity coefficient are 2.0, 0.9 and 0.6 for FC0, FC0.2 and FC0.4 respectively. The sorptivity coefficient of FC0.2 was $55 \%$ lower than FC0, whereas the sorptivity coefficient of FC0.4 was $70 \%$ lower than FC0 and $15 \%$ lower than FC0.2. The incorporation of CS into foamed concrete mix had resulted in the huge decrease in sorptivity as compared to FC0. The water repelling nature of CS had increased the water tightness of foamed concrete specimens. Thus, the sorptivity of FC 0.2 and FC0.4 were reduced by a huge margin.

\section{Conclusions}

Based on the experimental results, the following conclusions had been drawn to this study.

1. The optimum water-to-cement ratio of 0.48 was obtained from the trial mix and used as the reference mix for the specimens containing calcium stearate.

2. The incorporation of water repellents, which was CS in this study, had reduced the compressive strength.

3. There is an improvement for the foamed concrete with calcium stearate in terms of water absorption, initial surface absorption and sorptivity. The rate had reduced as the dosage of calcium stearate increased.

4. It was also found that $0.4 \%$ of calcium stearate in foamed concrete had caused the long term adverse effects on its compressive strength. Therefore, the recommended dosage for Calcium stearate incorporation is $0.2 \%$ of cement weight.

The authors gratefully acknowledge the financial support of the Universiti Tunku Abdul Rahman Research Fund (6200/LL4). The authors also express sincere gratitude for the assistance from Tan Thean Long, Low Sheng Keat and the technical staff from Laboratory at Department of Civil Engineering in Faculty of Engineering and Science, Universiti Tunku Abdul Rahman (UTAR).

\section{References}

1. P.K. Mehta, Concrete: Structure, properties and materials (1986)

2. M.N. Haque, H. Al-Khaiat, O. Kayali, Cement Concrete Comp, 26(4), 307-314 (2004)

3. K. Ramamurthy, E.K. Nambiar, G.I.S.Ranjani, Cement Concrete Comp, 31(6), 388396 (2009)

4. N. Narayanan, K. Ramamurthy, Cement Concrete Comp, 22(5), 321-329 (2000)

5. I. Patrov, E. Schlegel, Cement Concrete Res, 24(5), 830-840 (1994)

6. J. Alexanderson, Cement Concrete Res, 9(4), 507-514 (1979)

7. P. Russell, Concrete Admixtures (1983)

8. A.K. Suryavanshi, R.N.Swamy, Cement Concrete Res, 32(11), 1783-1789 (2002)

9. A. Maryoto, Procedia Engineer, 171, 511-516 (2017)

10. W. De Muynck, A.M. Ramirez, N. De Belie, W. Verstraete, Int Biodeter Biodegr, 63(6), 679-689 (2009)

11. ASTM, Standard Specification for Flow Table for Use in Tests of Hydraulic Cement ASTM C230-08 (2008) 
12. BSI, Testing hardened concrete - Part 3: Compressive strength of test specimens BS EN 12390 (2009)

13. ASTM, Standard Test Method for Density, Absorption, and Voids in Hardened Concrete ASTM C642-13 (2013)

14. BSI, Testing concrete - Part 208: Recommendations for the determination of the initial surface absorption of concrete BS 1881-208:1996 (1996)

15. ASTM, Standard Test Method for Measurement of Rate of Absorption of Water by Hydraulic-Cement Concretes ASTM C1585-04 (2004)

16. S.K.Lim, C.S.Tan, O.Y.Lim, Y.L.Lee, Construction and Building Materials, 46, 39-47 (2013) 